\title{
A Dimorphic and Virulence-Enhancing Endosymbiont Bacterium Discovered in Rhizoctonia solani
}

Ken Obasa and Frank F. White, Department of Plant Pathology, University of Florida, Gainesville 32611; John Fellers, U.S. Department of Agriculture-Agricultural Research Service Hard Winter Wheat Genetics Research Unit, Manhattan, KS 66506; Megan Kennelly and Sanzhen Liu, Department of Plant Pathology, Kansas State University, Manhattan 66506; Benjamin Katz, Biotechnology and Proteomics Core Facility, Kansas State University, Manhattan 66506; John Tomich, Department of Biochemistry and Molecular Biophysics, Kansas State University, Manhattan 66506; David Moore and Heather Shinogle, Microscopy and Analytical Imaging Laboratory, University of Kansas, Lawrence 66045; and Karen Kelley, Interdisciplinary Center for Biotechnology Research, University of Florida, Gainesville 32611

Accepted for publication 30 December 2016.

\section{ABSTRACT}

The ubiquitous soilborne and plant-pathogenic basidiomycete Rhizoctonia solani, although classified as a single species, is a complex of anastomosis groups (AGs) that cause disease in a broad range of higher plants. Here, we investigated the persistent co-isolation of bacteria with $R$. solanifrom brown patch-infected, coolseason turfgrasses, and report the presence of endo-hyphal bacteria, related to members in the genus Enterobacter, in an isolate of $R$. solani AG 2-2IIIB. The intracellular localization of the bacteria was corroborated by fluorescence, confocal and electron microscopy, and DNA analysis. Furthermore, the Enterobacter sp., which is rod-shaped in the free-living form, exists as an L-form (spheroid) within the fungus, a phenomenon not previously reported in endosymbionts. Our findings also indicate that the bacterium is required for full virulence of $R$. solani on creeping bentgrass and production of wild type levels of the toxin phenylacetic acid in fungal cultures. The possible presence of bacterial endosymbionts in $R$. solani AG 2-2IIIB may portend the presence of bacteria in additional AGs as well as other Rhizoctonia species, and may help resolve some of the complexities of $R$. solani pathogenicity. A closely associated bacterium could influence aspects of plant host pathology.

Additional keywords: ecology, endophytes, microbiome, microorganism, mycology, plant pathology, symbiosis.
The interplay of organisms in the plant microbiome is critical for understanding the processes of health and disease, and fungalbacterial interactions are an important but relatively understudied component of soil and plant microbiomes (Kobayashi and Crouch 2009). Interactions within microbiomes can include endosymbiotic relations, which metagenomics studies suggest are widespread and diverse (Hoffman and Arnold 2010). The ectomycorrhizal fungus

Corresponding authors: K. Obasa and F. F. White; E-mail addresses: obasa@ufl.edu and ffwhite@ufl.edu

*The $\boldsymbol{e}$-Xtra logo stands for "electronic extra" and indicates that one supplementary file is published online.

Author contributions. K.O. discovered the association and conducted the experiments. K.O., J.F., M.K., J.T., and F.W. designed experiments and analyzed data, and K.O. and F.W. wrote the manuscript. Phenylacetic acid analysis was performed by B.K., K.O., and J.T.; microscopy analysis was conducted by D.M., H.S., K.K., and K.O. GBS sequence data analysis was performed by S.L.

(C) 2017 The American Phytopathological Society
Laccaria bicolor, for instance, contains a species of endocellular bacteria from the genus Paenibacillus (Bertaux et al. 2003). Endosymbiotic bacteria also occur in the arbuscular mycorrhizal Glomeromycota fungi. Gigaspora margarita, the best studied host, forms arbuscular mycorrhizae and harbors 'Candidatus Glomeribacter gigasporarum', which is an obligate symbiont and transmitted through fungal spores (Bianciotto et al. 2004). However, no bacterial symbiont of mycorrhizal fungi has been cultured independent of the host, and few genetic analyses have been conducted (Kobayashi and Crouch 2009). In all these cases, a broader understanding of the contribution, if any, of the bacteria symbionts to the lifestyle of this mycorrhizal fungi are needed.

Reported cases of endosymbiotic bacteria in plant-pathogenic fungi are relatively few. Bacteria play a role in the virulence of the zygomycete fungus Rhizopus microsporus and strains of the fungus deploy one of two phytotoxins; rhizoxin, a virulence factor in rice seedling blight and rhizonin, an antifungal toxin (Partida-Martinez and Hertweck 2005; Partida-Martinez et al. 2007). These toxins are produced by the endosymbiotic bacteria Burkholderia rhizoxinica 
sp. nov. and B. endofungorum sp. nov., respectively. More recently, an association between the bacterium Pantoea ananatis (syn. Erwinia uredovora) and urediniospores of Puccinia arachidis, the causal agent of peanut rust, has also been reported, although an involvement in virulence is unknown (Arias et al. 2013).

Rhizoctonia species are an ecologically diversified group of binucleate and multinucleate fungal plant pathogens, soil saprophytes, and mycorrhizal partners of some orchids (Ogoshi 1987) and are widespread in many different soil types. Rhizoctonia solani (teleomorph: Thanatephorus cucumeris (A. B. Frank) Donk) is a species complex comprising many related but genetically isolated subspecific groups called anastomosis groups (AGs) (Anderson 1982; Carling 1996; Ogoshi 1987). AGs are established on the basis of the ability to form hyphal fusion (Carling 1996). Members of an AG are commonly found in infections in particular host plants, but nonpathogenic and hypovirulent strains are also encountered (Bandy and Tavantzis 1990; Sneh et al. 1989). The genetic basis for the loss of virulence is unknown. Hypovirulence has been attributed, in some cases, to mycoviruses that have been found in $R$. solani (Tavantzis and Lakshman 1995; Zheng et al. 2014). Evidence from studies of the infection process has suggested that extracellular enzymes including pectinolytic and cellulolytic enzymes are employed in host-plant penetration by members of some AGs (Bertagnolli et al. 1996; Brookhouser and Weinhold 1979; González-García et al. 2006). During the colonization of host-plant tissues after penetration, $R$. solani will also secrete the enzymes DNAse, RNAse, alpha-amylase, chitinase, beta-glucanase, xylanase, protease, and urease (Bertagnolli et al. 1996), but their involvement in host-plant colonization is not well understood (Bertagnolli et al. 1996). Several toxins, some of which may be involved in pathogenesis, have been reported to be produced by $R$. solani. A host-specific complex toxin has been reported that is capable of reproducing symptoms of rice sheath blight and contains glucose, mannose, $N$-acetylgalactosamine, and $N$-acetylglucosamine (Vidhyasekaran et al. 1997). An uncharacterized phytotoxin from $R$. solani was also reported to correlate with sheath blight development in rice (Brooks 2007). Other phytotoxins identified from $R$. solani have included phenylacetic acid (PAA), one or more hydroxyl derivatives of PAA (Liu and Sinclair 1993), and fumaric acid (Hoffman and Jongebloed 1988).

$R$. solani, as a group, is known to infect species of higher plants in at least 32 families, including cereals, vegetable crops, ornamentals, and turfgrasses (Partida-Martinez et al. 2007). Strains of $R$. solani AG 2-2IIIB infect cool-season turfgrasses and a variety of other hosts, including rice and sugar beets (Herr 1996). The disease incited by $R$. solani AG 2-2IIIB on turfgrass is known as brown patch. Isolations of $R$. solani from diseased tissue led to the observation that the hyphae were persistently associated with bacteria during growth on solid media. Here, we investigated the association of $R$. solani AG 2-2IIIB and bacteria that were concomitantly isolated from brown patch-infected leaves of creeping bentgrass (Agrostis stolonifera L.). Specifically, we sought to investigate the fungus for intracellular localization by the bacteria, and potential role of the bacterium in virulence and production of the toxin, PAA, by the fungus.

\section{MATERIALS AND METHODS}

Fungal isolation, identification, and storage. $R$. solani isolates were cultured from infected leaves of A. stolonifera in a mixed stand of cultivars 'Crenshaw' and 'Cato'. Three leaf sections were excised and surface-sterilized with $0.5 \% \mathrm{NaOCl}$ for $2 \mathrm{~min}$, blotted dry, and placed on 1/4 strength potato dextrose agar (1/4 PDA) plates (Difco Laboratories, Baltimore, $\mathrm{MD})$ at room temperature $\left(23^{\circ} \mathrm{C}\right)$ in the dark. Hyphal tips from one selected clone, designated as Rs-Cren, were transferred onto fresh 1/4 PDA, and cultures were either subsequently stored directly at $4^{\circ} \mathrm{C}$ or mycelial plugs were transferred into $20 \%$ glycerol and stored at $-80^{\circ} \mathrm{C}$. AG typing of Rs-Cren was done on the basis of hyphal anastomosis with an AG 2-2IIIB reference isolate, " $\mathrm{Rh}$ 146", isolated from creeping bentgrass and kindly provided by Lee Burpee, as previously described (Carling 1996; Yokoyama et al. 1985) and by polymerase chain reaction (PCR) using AG 2-2IIIB-specific primers as previously described (Carling et al. 2002). The AG grouping experiments each consisted of two replicates. The PCR fragment sequence was determined by Sanger sequencing and deposited as NCBI accession KX377959.

Fungal genomic DNA extraction and bacterial 16S rDNA amplification. Mycelia were grown in complete media (CM) broth (Correll et al. 1987) from 5-mm-diameter agar discs for 5 days at $23^{\circ} \mathrm{C}$ in the dark. After incubation, mycelia were collected by filtration and ground into fine powder in liquid nitrogen followed by extraction of genomic DNA. To detect bacterial DNA in the fungal culture, PCR analysis of $16 \mathrm{~S}$ rDNA consisted of $10 \times \mathrm{NH}_{4}$ buffer, $50 \mathrm{mM} \mathrm{MgCl}_{2}, 25 \mathrm{mM}$ dNTP, 0.5 units of Taq polymerase (Bioline, Taunton, MA), $5.0 \mu \mathrm{M}$ concentration of the $16 \mathrm{~S}$ rDNA forward primer (ER10: GGCGGACGGGTGAGTAA) and reverse primer (ER11: ACTGCTGCCTCCCGTAG) (Myra et al. 1994), respectively, and $50 \mathrm{ng} / \mu \mathrm{l}$ of gDNA. The PCR was programmed on an MJ Research PTC-100 Peltier DNA thermal cycler (Bio-Rad, Hercules, $\mathrm{CA}$ ) with an annealing temperature of $55^{\circ} \mathrm{C}$. Two independent PCR analyses were performed for each analysis of the wild-type Rs-Cren isolate and derivatives, described below.

Mycelia growth measurements. To compare growth of wildtype Rs-Cren and derivative strains, three replicates of a 5-mm diameter agar plug of mycelia were placed on PDA in 8-cm-diameter Petri dishes and incubated in the dark at room temperature $\left(23^{\circ} \mathrm{C}\right)$ for 3 days. Radial growth within each plate was subsequently measured and expressed as the average diameter along two predrawn perpendicular lines on the underside of each Petri dish. Mycelia dry weights were determined as previously described (Siddiqui and Shaukat 2005). Briefly, an agar plug of mycelia was incubated in $\mathrm{CM}$ broth contained in $250-\mathrm{ml}$ conical flask in the dark, at room temperature $\left(23^{\circ} \mathrm{C}\right)$ for 21 days. Three cultures were established for each strain. The resulting mycelia were separated from the broth by filtering through two layers of Whatman No. 1 filter paper, dried at $80^{\circ} \mathrm{C}$ for $48 \mathrm{~h}$, and weighed. The dry weight measurement study was conducted twice, with independent preparations of each culture.

Isolation of bacterial endosymbiont, generation of bacteriafree fungus, and fungus-bacteria co-culture. Mycelia of Rs-Cren grown in $\mathrm{CM}$ broth was surface-sterilized by submerging once in $70 \%$ alcohol for $2 \mathrm{~min}$ and rinsed in five changes of sterile-filtered deionized water (18 megohm). The fifth and final rinsate was collected. Aliquots of the final rinse solution were plated on Luria Bertani (LB) agar and incubated overnight at $30^{\circ} \mathrm{C}$ to determine possible bacterial contamination. The rest of the final rinse solution was concentrated by centrifugation in a microcentrifuge at 14,000 rpm for $5 \mathrm{~min}$ and analyzed by PCR for bacterial 16S rDNA fragments. The surface-sterilized mycelia were then disrupted in a 2-ml tube containing 0.5-mm-diameter zirconia/silica beads (Biospec, Bartlesville, OK) and $500 \mu \mathrm{l}$ of LB broth, with or without chloramphenicol for translation inhibition, using an MP-Bio FastPrep-24 (MP Biosciences, Irvine, CA) bead-beater in a single cycle at speed 4.0 for $45 \mathrm{~s}$. An aliquot of the supernatant was subsequently plated on $\mathrm{LB}$ agar and incubated at $28^{\circ} \mathrm{C}$ to obtain bacterial colonies, if present, or further processed for scanning and transmission electron microscopy. Each experiment was repeated twice. Bacteria-free strains of wild-type Rs-Cren (heretofore cured-Rs-Cren; GenBank accession number KX377960) was generated by two serial cultures of Rs-Cren 
for $48 \mathrm{~h}$ and then $72 \mathrm{~h}(1 \times)$ in $1 / 4 \mathrm{PD}$ broth amended with tetracycline at $30 \mu \mathrm{g} / \mathrm{ml}$; Biotech Research Grade, Fisher Scientific Inc., New Jersey). To establish a co-culture with bacteria or to evaluate for localization of bacteria along hyphal walls, cultures of the fungus and bacteria were grown separately on $1 / 4 \mathrm{PDA}$ at $23^{\circ} \mathrm{C}$ and LB agar at $30^{\circ} \mathrm{C}$, respectively. A 3-day-old culture of cured-Rs-Cren on 1/4 PDA was inoculated with bacteria. A sterile pipette tip was used to transfer bacteria from a single colony of an overnight culture on LB agar onto the fungus-colonized 1/4 PDA plate at about $0.5 \mathrm{~cm}$ in front of the hyphal tip. The advancing fungal hyphae subsequently grew up to and through the bacterial colony and grew on to the edge of the plate. A subculture of the resultant mixture (restored-Rs-Cren or restoredRs-Cren ${ }^{\text {GFP }}$ ) was subsequently transferred onto fresh 1/4 PDA and stored at $4^{\circ} \mathrm{C}$. Bacterial strains were re-established within hyphae of cured-Rs-Cren in two independent experiments.

Bentgrass plant inoculations, disease assessment, and rice leaf sheath inoculation assay. Metro Mix 510 potting media (SUN GRO., Agawam, MA) contained in plastic pots $\left(5 \times 5 \mathrm{~cm}^{2}\right)$ were seeded with creeping bentgrass cultivar Crenshaw. Pots were watered daily with sterile water and maintained at $30^{\circ} \mathrm{C}$ and $13 \mathrm{~h}$ photoperiod in a greenhouse. After 21 days, pots were inoculated by placing a 3-day-old, 5-mm-diameter 1/4 PDA plug of fungus on the soil surface at the center of each pot. Pots inoculated with agar plugs alone served as controls. Inoculated pots of each treatment, replicated thrice, were then arranged in separate plastic trays filled with sterile water to a depth of 2 to $3 \mathrm{~cm}$. Each tray was covered with a clear plastic lid to maintain a high relative humidity $(>90 \%)$, arranged in a complete randomized design, and further maintained at $30^{\circ} \mathrm{C}$ and a $13 \mathrm{~h}$ photoperiod. After 21 days of incubation, digital images of an area $\left(3 \times 3 \mathrm{~cm}^{2}\right)$ around the center of each pot was taken using the automatic settings of a Nikon D70s digital camera (Nikon Inc., Japan). Analysis of the percentage of disease within each image was done as described previously (Obasa et al. 2013) using SigmaScan Pro ver. 5.0 (SPSS, Chicago, IL) image analysis software (hue: 0 to 53, and saturation: 0 to 57, respectively), and a SigmaScan Pro macro for batch analysis of digital images named "Turf Analysis" (Karcher and Richardson 2005).

Microscopy. For fluorescence microscopy, a 10-mm-diameter mycelial plug of $R$. solani was incubated on a thin block of water agar on a glass slide. After $48 \mathrm{~h}, 500 \mu \mathrm{l}$ of diluted SYTO 9 green fluorescent nucleic acid stain (Molecular Probes Cat. No. L7007; Waltham, MA) $(10 \mu \mathrm{l}$ of SYTO $9+490 \mu \mathrm{l}$ of Mcllvaine buffer) was added to the hyphal growth and incubated for $2 \mathrm{~min}$ at room temperature. The slide was then washed with $3 \mathrm{ml}$ of Mcllvaine buffer to remove excess staining solution. The slides were subsequently mounted with one drop of the fluorescence enhancer, Vectashield (Vector Cat. No. H-1000; Burlingame, CA), covered with a thin glass coverslip $(24 \mathrm{~mm} \times 30 \mathrm{~mm}$ Fisher Co. $)$ and analyzed using a Zeiss LSM 700 confocal fluorescent microscope at $488 \mathrm{~nm} / 555 \mathrm{~nm}$. The intrahyphal localization of the endosymbiont En-Cren was further investigated by confocal fluorescence (CF) and scanning electron (SE) microscopy. For CF microscopy, Enterobacter sp. strain En-Cren was engineered to express the green fluorescent protein (GFP) from a pHM1-GFP or pBAV1KT5-GFP plasmid vector (Bryksin and Matsumura 2010) (designated En-Cren ${ }^{\mathrm{GFP}}$ ) by electroporation, and subsequently introduced into cured-Rs-Cren (restored-Rs-Cren ${ }^{\text {EnGFP }}$ ). GFP-expressing bacteria cells were visualized using an Olympus IX81/31 spinning disk confocal inverted microscope at $488 \mathrm{~nm}$. For the rice leaf sheath assay, rice stems measuring about $5 \mathrm{~cm}$ in length from a 2-week-old rice plant were cut with a sterile scissor and inoculated at one end with a 1/4 PDA plug of fungus. Inoculated stems were incubated on moistened filter paper in a Petri dish and maintained at room temperature $\left(\sim 23^{\circ} \mathrm{C}\right)$ and a $13 \mathrm{~h}$ photoperiod. After 3 days, leaf sheath sections from the inoculated stems were prepared as previously described (Kankanala et al. 2007). For SE microscopy, intact or disrupted mycelia were fixed in $4 \%$ paraformaldehyde, postfixed with or without osmium tetroxide (2\%) for $10 \mathrm{~min}$, dehydrated in a graded alcohol series and critical point dried. Dried samples were sputter coated with $5 \mathrm{~nm}$ of either gold/palladium or copper using a Quorum EMS150T S sputter coater (QuorumTech, Laughton, East Sussex, UK). Gold/palladium coated samples were imaged using a Carl Zeiss Field Emission Scanning Electron Microscope and copper coated samples were examined by simultaneous secondary electron imaging (SEI) and backscatter electron imaging (BEI) using an FEI Versa 3D dual beam (FEI, Hillsboro, $\mathrm{OR})$. Images were collected with a $10 \mathrm{kV}$ electron beam and a spot size of $4(10 \mathrm{pA})$ using an Everhart-Thornley detector. For dual beam images, samples were milled using a $30 \mathrm{kV}$ gallium ion beam, with a current ranging from $30 \mathrm{pA}$ to $3 \mathrm{nA}$ depending on rate of milling necessary. Regular transmission electron (TE) microscopy protocol was similar to that for the SE microscopy with the exception that ethanol dehydration was followed with additional dehydration with $100 \%$ acetone and infiltrated in a graded series of acetone/Embed812-Araldite epoxy resin (30, 50, 70, and $2 \times$ $100 \%$ ). Resin-infiltrated samples were cured at $60^{\circ} \mathrm{C}$ for $48 \mathrm{~h}$. For high-pressure freezing/freeze substitution, briefly, samples were placed in specimen planchettes containing 1-Hexadecene as a cryoprotectant, then high-pressure frozen in a Leica HPM100 high-pressure freezer (Leica Microsystems, Buffalo Grove, IL) at $-180^{\circ} \mathrm{C}, 2100$ bar and maintained under liquid nitrogen. For optimal ultrastructural analysis, samples were transferred to freeze substitution medium (anhydrous acetone containing 2\% osmium tetroxide, $0.1 \%$ uranyl acetate) under liquid nitrogen and placed in the Leica AFS2 freeze substitution system (Leica Microsystems) precooled to $-130^{\circ} \mathrm{C}$. For freeze substitution, the samples were brought to $-90^{\circ} \mathrm{C}$ over $1 \mathrm{~h}$, remaining at $-90^{\circ} \mathrm{C}$ for $24 \mathrm{~h}$, and subsequently warmed to $-20^{\circ} \mathrm{C}$ over a period of $18 \mathrm{~h}$. Samples were held at $4^{\circ} \mathrm{C}$ for 30 min prior to washing with anhydrous acetone at room temperature, and subsequently infiltrated and embedded in LR White Hard resin. Resin cured sample blocks were sectioned with a Leica Ultracut UCT ultramicrotome (Leica Microsystems Inc., Bannockburn, IL), stained with uranyl acetate and lead citrate, examined with FEI Tecnai G2 Spirit Twin TEM (FEI Corp., Hillsboro, OR) and digital images were acquired with a Gatan UltraScan $2 \mathrm{k} \times 2 \mathrm{k}$ camera and Digital Micrograph software (Gatan Inc., Pleasanton, CA). Anti-Enterobacter outer membrane protein-A (OmpA) polyclonal antibody (Antibody Research Corporation, St. Charles, MO) was used at a dilution of 1:100 in $1 \times$ bovine serum albumin (BSA). Alexa Fluor 488 FluoroNanogold Conjugate, with a $1.4 \mathrm{~nm}$ gold particle (Cat. No. 7204; Nanoprobes, Inc., Yaphank, NY) was used as secondary antibody for TE microscopy imaging at a dilution of 1:500 in 1× BSA. All electron microscopy studies were conducted twice with independent preparations of fungal samples.

PAA quantification. PAA production by the fungus was evaluated in CM broth. Twenty-one-day-old spent fungal broth cultures were filter-sterilized using a $0.2 \mu \mathrm{m}$ filter (Fisher Scientific, Hudson, $\mathrm{NH}$ ) and immediately transferred to storage at $-80^{\circ} \mathrm{C}$. Prior to detecting and quantifying PAA from the liquid media, interfering contaminants such as salts and sugars were removed by liquid/liquid extraction. In a 1.5-ml microfuge tube, $500 \mu \mathrm{l}$ of the sterile media was spiked with $2.5 \mu \mathrm{g}$ of the standard d7-PAA such that the final concentration was $500 \mathrm{ng} / \mu \mathrm{l}$. The spiked sample was then mixed with $50 \mu \mathrm{l}$ of saturated $\mathrm{NaCl}$ solution and $50 \mu \mathrm{l}$ of $1.0 \mathrm{M}$ $\mathrm{HCl}$ to acidify the buffered growth media. Ethyl acetate was used as the extraction solvent in a 1:1 ratio. The sample was vigorously vortexed for $30 \mathrm{~s}$ and then left to separate at $4^{\circ} \mathrm{C}$ for $30 \mathrm{~min}$. The 
sample was then centrifuged to break the emulsion and $200 \mu \mathrm{l}$ of the ethyl acetate (supernatant) was transferred to a new microfuge tube. The solvent was removed under vacuum and reconstituted to $50 \mu \mathrm{l}$ using $70 \%$ ethanol containing $0.01 \%$ formic acid. An injection volume of $5 \mu \mathrm{l}$ was separated isocratically across a C18 Synergi $2.5 \mu \mathrm{m}$ HydroRP 100A $20 \times 20 \mathrm{~mm}$ column (Phenomenex, Torrance, CA), on an Agilent 1100 series HPLC at $0.5 \mathrm{ml} / \mathrm{min}$ for $10 \mathrm{~min}$. Mass spectrometry analysis was performed in tandem on a Bruker Esquire 3000 electrospray ion trap MS/MS at $4000 \mathrm{~V}$ and $200^{\circ} \mathrm{C}$ in negative mode using multi reaction monitoring (MRM) with 12 psi nebulizing and 5 liters of dry gas per minute. The parent ions of PAA from both the media and standard preparations (135.3 and 142.3 $\mathrm{Da}$ ) were isolated with the ion trap at $100 \mathrm{~ms}$ and the respective daughter ions, 90.7 and $97.7 \mathrm{Da}$, were used for confirmation. The integrated daughter ion area across the HPLC elution time (1.8 to 2.1 min) was used for quantification by comparing the PAA area to the d7PAA internal standard compared with a concentration curve. Quantification of PAA from $R$. solani and bacteria was performed in two independent experiments with three replicated samples per treatment. The limit of detection and limit of quantification for this assay were determined to be 1 and $10 \mathrm{ng} / \mu \mathrm{l}$, respectively. Data analysis was performed with Minitab statistical software (version 16; Minitab Inc., State College, PA). The data for PAA concentration were subjected to analysis of variance. Mean comparisons were performed using Fisher's individual error rate at $P \leq 0.05$.

Phylogenetic analysis. A library was prepared from bacterial genomic DNA using the Illumina TruSeq DNA LT Sample Prep kit (Illumina, San Diego, CA). In addition, $2 \times 250$-bp paired-end data were generated on an Illumina MiSeq at the Integrated Genomic Facility at Kansas State University. Reads were trimmed and assembled via CLC Genomics Workbench software or SOAPdenov2 (Li et al. 2010). The sequence for $p t s P$, gyrB, and recA (NCBI accessions KX550436, KX550437, and KX550438, respectively) were trimmed, concatenated, and aligned to concatenated representative genes from other enterics by BLASTN. A phylogenetic tree was constructed using FASTME (http://blast.ncbi.nlm.nih.gov/ Blast.cgi?PROGRAM = blastn\&PAGE_TYPE =BlastSearch\&LINK_ $\mathrm{LOC}=$ blasthome) (Desper and Gascuel 2004). The ptsP, gyrB, and $r e c A$ sequences were selected from the following genomic data: E. coli W, CP002185; Dickeya dadantii Ech586, CP001836; Enterobacter asburiae LF7a, CP003026; Enterobacter cloacae subsp. cloacae ATCC 13047, CP001918; Pectobacterium carotovorum subsp. carotovorum PC1, CP001657; Salmonella enterica subsp. enterica SL483, NC_011149, and Yersinia pestis KIM 10, AE009952. The sequence and full assembly of Enterobacter sp. En-Cren genome will be presented elsewhere.

Genotyping-by-sequencing (GBS) and alignment. To determine if antibiotic treatment of Rs-Cren caused any unintended genetic change in the resultant cured-Rs-Cren strain, comparisons of the DNA sequence of both strains was done. Wild-type and cured-RsCren were subjected to genomic DNA extraction and a modified GBS with a methylation insensitive enzyme of Bsp1286I (Elshire et al. 2011). GBS data were trimmed to remove low-quality sequences with Trimmomatic 3.2 (Bolger et al. 2014) and then aligned to the assembly sequence of $R$. solani AG 2-2IIIB (GenBank accession number GCA_001286725.1) through BWA (0.7.5a-r405) (Li and Durbin 2009). The criteria of $\geq 40$ mapping score, at least $40 \mathrm{bp}$ matches with $\geq 96 \%$ identity and $\leq 4 \%$ unaligned tail, and an insertion size of between $100 \mathrm{bp}$ and $1 \mathrm{~kb}$ were used to filter alignments. Single nucleotide polymorphisms (SNPs) were identified through using the filtered alignments of GBS reads to the assembly sequence of $R$. solani AG 2-2IIIB. SNPs were initially identified through the GATK pipeline (McKenna et al. 2010). A minimum of eight supporting reads were required for SNP calls.
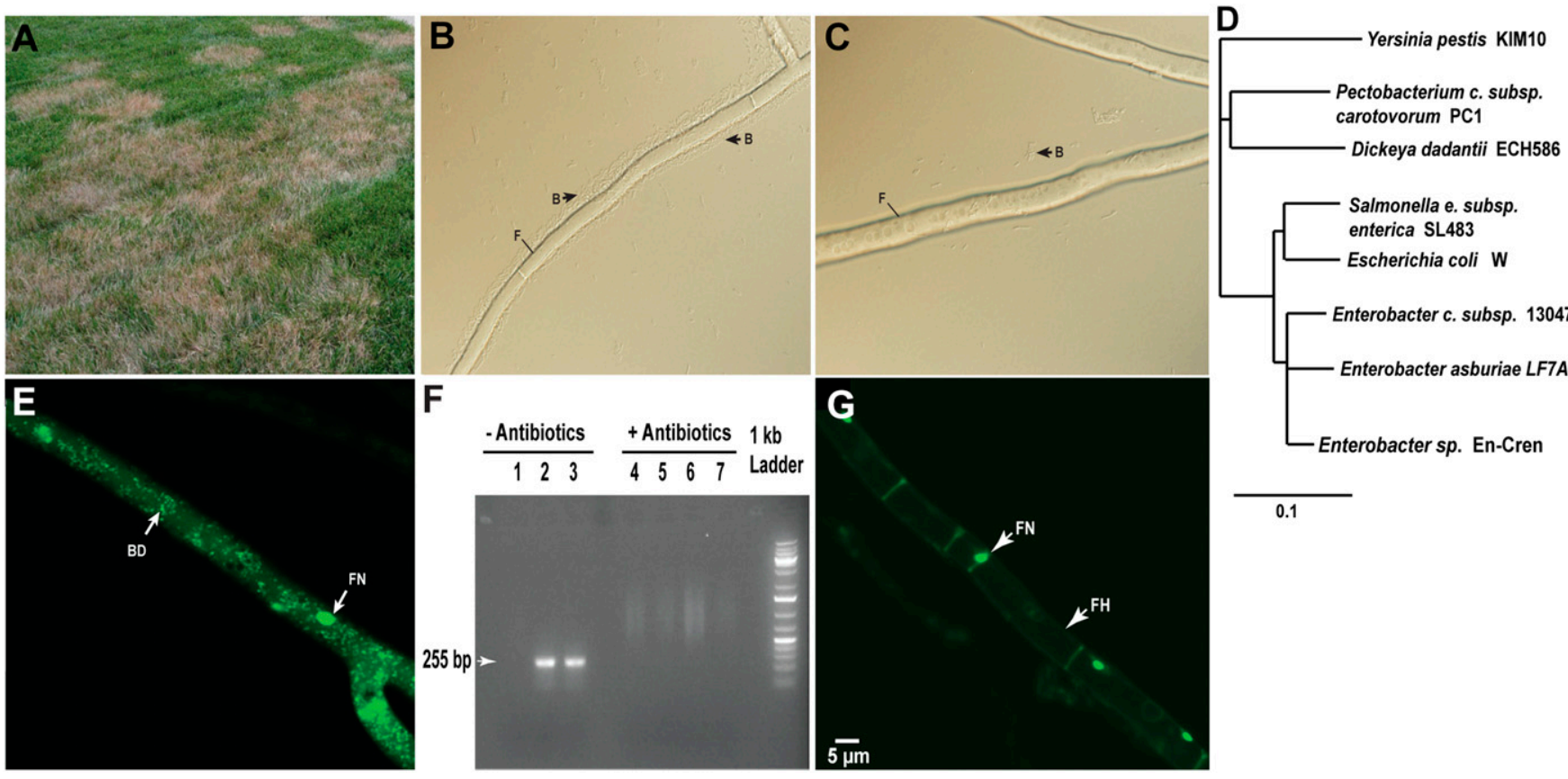

Enterobacter sp. En-Cren

0.1

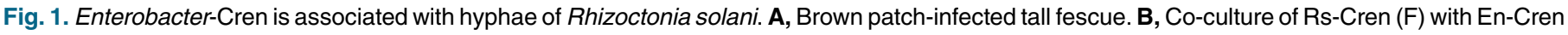
$(\mathrm{B})$, and C, Escherichia coli (B). D, Phylogenetic relationship of Enterobacter sp. En-Cren based on multilocus sequence analysis of ptsP, gyrB, and recA. Bar represents distance of substitutions per base. E, Fluorescence microscopy of SYTO 9-stained hyphae of Rs-Cren showing fungal

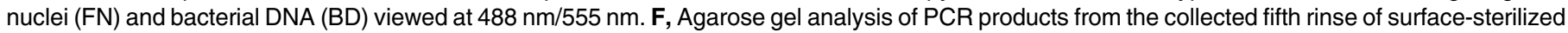

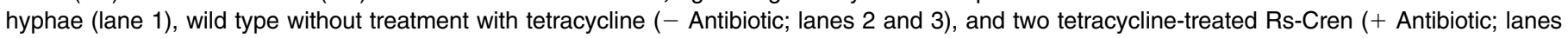

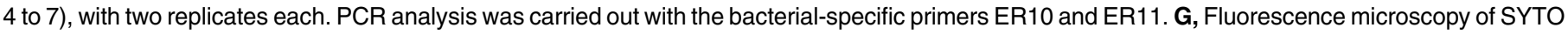
9-stained hypha $(\mathrm{FH})$ of cured-Rs-Cren showing stained fungal nuclei (FN). 
Read variation between two strains were derived from alignments passing the filtering criteria and quantification of read depths in nonoverlapping windows with the size of $20 \mathrm{~kb}$ on each contig of the assembly sequence of $R$. solani AG 2-2IIIB. Reads per million of aligned total reads (RPM) of each sample were calculated for each window for read variation normalization. Only the windows of which the total RPM value of both wild-type and cured samples is greater than 200 were used for the comparison between two strains.

\section{RESULTS}

Bacteria are associated with $\boldsymbol{R}$. solani hyphae. $R$. solani strain Rs-Cren was isolated from A. stolonifera (creeping bentgrass) and
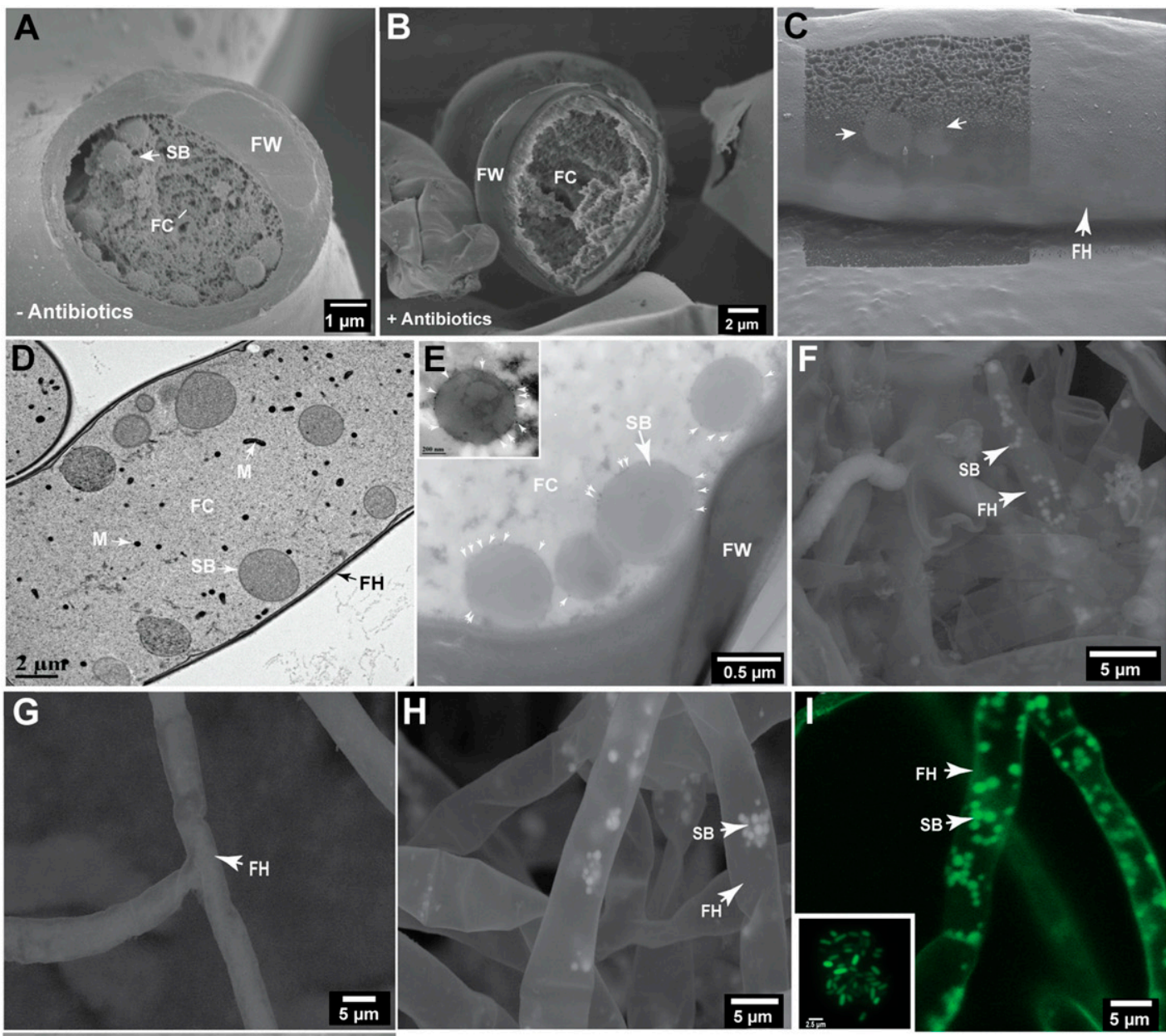

$5 \mu \mathrm{m}$

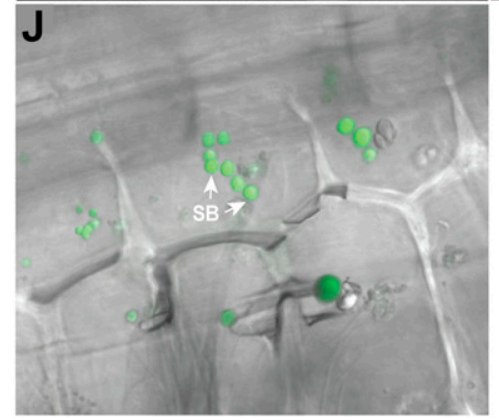

Fig. 2. Visualization of endohyphal bacteria in Rhizoctonia solani Cren. A, Scanning electron (SE) microscopy of transverse section of Rs-Cren showing fungal wall (FW) and intracellularly localized spherical-shaped bodies (SB) within fungus cytoplasmic matrix (FC). B, Transverse section of cured-RsCren showing the lack of intracellular spherical-shaped bodies. C, Dual-beam SE microscopy of milled cell wall of Rs-Cren hypha (FH) revealing the outline of intracellular spherical-shaped bodies (SB, small white arrows). D, Transmission electron (TE) microscopy of high-pressure freezing/freeze substitution Rs-Cren hypha (FH) showing intracellular spherical-shaped bodies and fungal mitochondria (M) within fungus cytoplasm (FC). E, TE microscopy of $1.4 \mathrm{~nm}$ immunogold-labeled OmpA (small white arrows) on spherical-shaped bodies (SB) in intact hypha of Rs-Cren, and an enlarged immunogold-labeled spherical body (inset). F, SE microscopy of osmium-treated Rs-Cren hyphae (FH) showing intracellularly localized sphericalshaped bodies (SB). G, Cured-Rs-Cren hyphae (FH) treated as in F. H, Hyphae (FH) of restored-Rs-Cren showing intracellular spherical-shaped bodies (SB) treated as in F. I, Confocal microscopy at $488 \mathrm{~nm} / 555 \mathrm{~nm}$ showing restored-Rs-Cren ${ }^{\text {EnGFP }}$ showing intracellular spherical-shaped En-Cren ${ }^{\text {GFP }}$, and free-living rod-shaped En-Cren ${ }^{\text {GFP }}$ (inset). J, Thin section of rice stem infected with Rs-Cren ${ }^{\text {EnGFP }}$ showing spherical-shaped En-Cren ${ }^{\text {GFP }}$-colonized rice cells. 
identified as a member of AG 2-2IIIB based on anastomosis and sequence analysis of AG-specific amplicon (Fig. 1A; Supplementary File S1). Upon culturing on 1/4 PDA and hyphal growth of Rs-Cren from agar plugs, bacteria were observed growing along with hyphae and in close association with the external hyphal walls of the fungus (Fig. 1B). However, the bacteria often were no longer visible around the hyphae under light microscopy after mycelia growth reached the edges of Petri dish and upon subsequent serial transfers. A similar close association of bacterial growth with fungal hyphae was not observed when inoculated with a laboratory strain of E. coli (Fig. 1C). The identity of the bacteria, following multiple single colony purifications and analysis by PCR with universal $16 \mathrm{~S}$ rDNA primers, was determined to be a single strain related to the family Enterobacteriaceae. Draft sequencing and multilocus sequence analysis comparisons of genes $p t s P$, gyrB, and $r e c A$ indicated that the bacterium was most closely related to members of the genus Enterobacter (heretofore Enterobacter sp. En-Cren) (Fig. 1D). Fluorescence microscopy of apparent bacterial free Rs-Cren hyphae, revealed, in addition to fungal nuclei, the presence of other DNA signals within the cytoplasm of Rs-Cren when stained with the DNAbinding fluorescent dye SYTO 9 (Fig. 1E). En-Cren did not exhibit a similar distinct association with the hyphae of other fungi evaluated including Fusarium graminearum, Sclerotinia homoeocarpa, and Magnaporthe oryzae (data not shown).

Bacterial DNA is detected within fungal hyphae. The location of bacteria was investigated in mycelia of Rs-Cren that were first surface-sterilized with alcohol and rinsed with sterile water. When an aliquot was plated, neither bacterial colonies nor 16S rDNA PCR-amplicons were detected from the final hyphal rinse (Fig. 1F, lane 1). At the same time, genomic DNA of two independent wildtype cultures of Rs-Cren was positive for bacterial rDNA (Fig. 1F, lanes 2 and 3). For comparison, DNA from mycelia of bacteria-free strains of cured-Rs-Cren were negative for bacterial 16S rDNA
(Fig. 1F, lanes 4 to 7). Fluorescence microscopy of the cured-RsCren strains revealed only fungal nuclei within hyphae (Fig. 1G). No bacterial colonies were cultured from disrupted hyphae of curedRs-Cren when plated on LB agar.

Visualization of endohyphal bacteria within fungal hyphae. To visualize bacteria within intact hyphae of Rs-Cren, attempts were made to view inside the ends of sheared hyphae by SE microscopy. In multiple fields of view in two independent preparations, spherical-shaped cells were observed inside the cut edge of hyphae of Rs-Cren, while no structures were observed in cured-RsCren (Fig. 2A and B). Examination of hyphae by laser assisted SE microscopy was also performed in which a section of hyphal cell wall was removed, revealing spherical-shaped cells (Fig. 2C). Spherical sections of cells were also observed in thin sections of RsCren by (TE) microscopy (Fig. 2D). However, the structures in wild-type Rs-Cren were not the expected rod-shaped structures of free-living Enterobacter species. At the same time, the binding of a gold-conjugated anti-Enterobacter (OmpA) antibodies to the membranes of the spherical bodies provided evidence that some of the bodies were, indeed, Enterobacter (Fig. 2E).

To gain a larger internal field of view into intact hyphae, two additional approaches were taken to visualize intracellular bacteria. Furthermore, and as a direct test of the ability of Enterobacter sp. En-Cren to enter hyphae and assume an atypical morphology, the bacterium was reintroduced into cured-Rs-Cren by co-cultivation of the bacteria with the fungus. The resulting fungus following reintroduction was named restored-Rs-Cren. In the first approach, membrane lipids stained with osmium tetroxide $\left(\mathrm{OsO}_{4}\right)$ were examined by simultaneous SEI and BEI. Spherical cells were visible within intact hyphae of Rs-Cren (Fig. 2F), while no structures indicative of bacteria were observed within hyphae of similarly treated cured-Rs-Cren (Fig. 2G). SEI/BEI microscopy of restoredRs-Cren, as with the wild-type fungus, revealed spherical-shaped
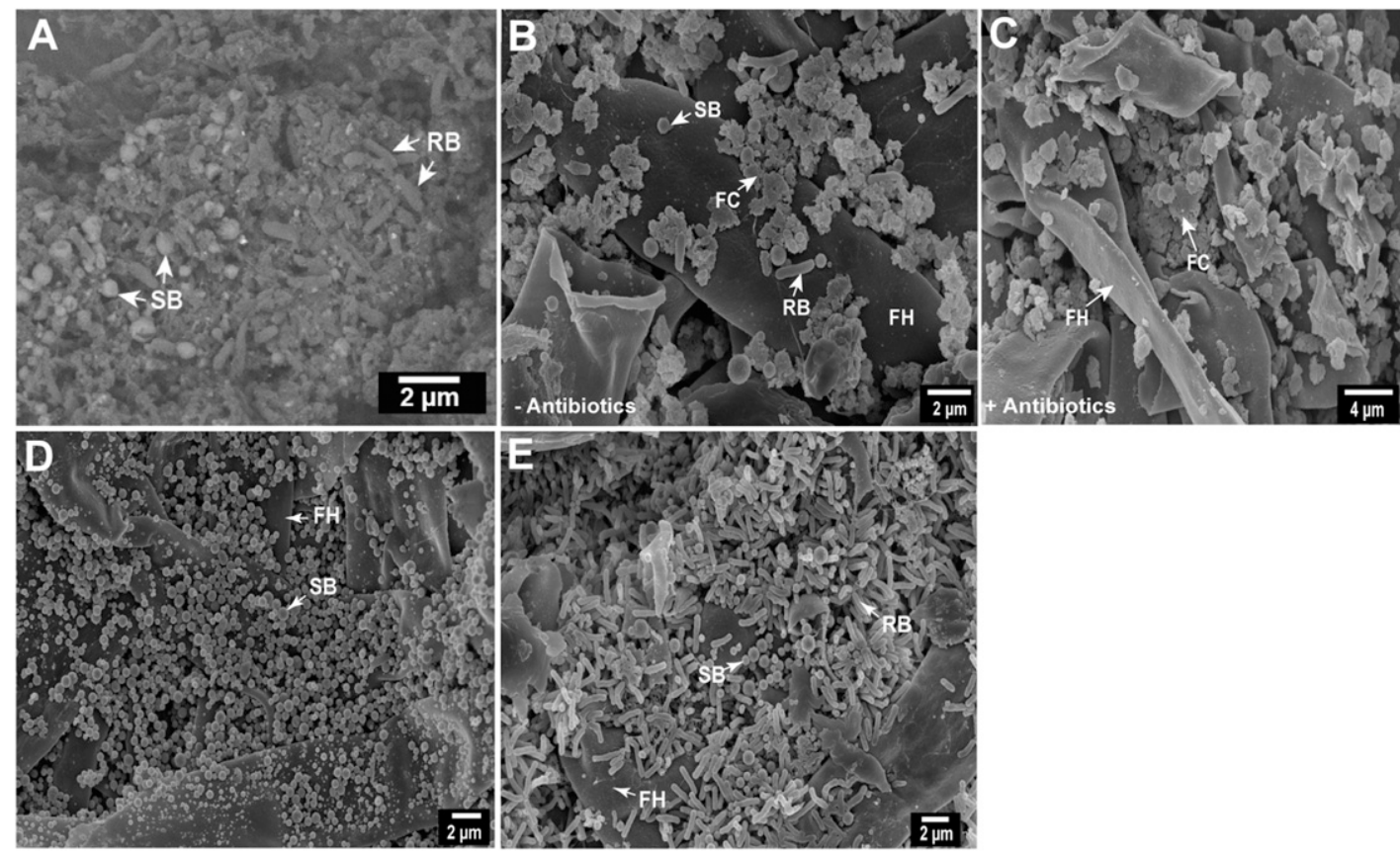

Fig. 3. Dimorphism in endo-hyphal Enterobacter-Cren. A, Disrupted mycelia of restored-Rs-Cren showing presence of spherical-shaped (SB) and rod-shaped (RB) bodies. B, Disrupted hyphae (FH) of Rs-Cren showing spherical-shaped bodies (SB) and rod-shaped bacteria (RB) among the fungal cytoplasmic matrix (FC). C, Absence of the rod- and spherical-shaped bodies in cured-Rs-Cren. D, Scanning electron microscopy of disrupted Rs-Cren mycelia with chloramphenicol treatment during disruption showing only spherical-shaped bodies (SB) interspersed among fungal hyphae (FH). E, Predominantly, rod-shaped bacteria cells (RB) with some spherical-shaped bodies (SB) and fungal hyphae (FH) of Rs-Cren following disruption, then incubation at room temperature for $20 \mathrm{~min}$. 
cells within intact hyphae of restored-Rs-Cren (Fig. 2H). The ability to reintroduce the bacterium allowed introduction of a genetically marked strain that expresses GFP. CF microscopy revealed GFP fluorescent spherical-shaped cells within restored-Rs-Cren ${ }^{\text {EnGFP }}$ hyphae (Fig. 2I). The morphology of En-Cren ${ }^{\text {GFP }}$ persisted in tissues of rice stems inoculated with restored-Rs-Cren ${ }^{\text {EnGFP }}$ that were examined by $\mathrm{CF}$ microscopy. To avoid interference due to chlorophyll auto-fluorescence, sheath cells from etiolated rice stems were used for the imaging microscopy. Extrahyphal EnCren ${ }^{\text {GFP }}$ were similarly observed as spherical cells in etiolated rice sheath cells that were infected by restored-Rs-Cren ${ }^{\text {EnGFP }}$ (Fig. 2J).

Enterobacter sp. En-Cren exhibits cellular dimorphism. Bacteria were harvested from disrupted mycelia of restored-RsCren and imaged by SE microscopy. In this approach, both spherical and some rod-shaped cells were observed (Fig. 3A). A similar observation was made with hyphae from wild-type Rs-Cren, while neither spherical- nor rod-shaped cells were observed from hyphae of cured-Rs-Cren (Fig. 3B and C, respectively). The absence of rod shaped cells in intact hyphae may indicate that bacteria cannot assume the typical rod shape without exposure to free-living conditions. The inclusion of chloramphenicol during the disruption of mycelia, to inhibit protein synthesis and, consequently, a shift from spherical- to rod-shaped cells, resulted in only sphericalshaped bodies in SE micrographs of Rs-Cren, whereas spherical and rod shapes were observed in the absence of chloramphenicol
(Fig. 3D and E). Enterobacter sp. En-Cren, therefore, can reassume a rod-shape form after brief exposure to free-living conditions.

Bacteria endosymbiont is required for enhanced virulence and PAA production by Rs-Cren. The virulence of Rs-Cren, cured-Rs-Cren, and restored-Rs-Cren strains was tested by inoculation of creeping bentgrass. The mock-inoculated control and cured-Rs-Cren resulted in minor symptoms (Fig. 4A, i and ii). Extensive necrosis developed after inoculation with both wild-type Rs-Cren and restored-Rs-Cren (Fig. 4A, iii and iv). Estimation of diseased area indicated that both wild-type Rs-Cren and restoredRs-Cren caused more damage than cured-Rs-Cren and the mockinoculated control (Fig. 4B). PAA may function as a virulence factor for some isolates of $R$. solani (Bartz et al. 2012). Measurements of PAA levels in 21-day-old spent CM cultures of curedRs-Cren, wild-type Rs-Cren, and restored-Rs-Cren found a fourfold reduction in PAA in cured-Rs-Cren when compared with Rs-Cren (Fig. 4C). PAA production by restored-Rs-Cren $(3.44 \mathrm{ng} / \mu \mathrm{l} / \mathrm{mg}$ ) was threefold greater than by cured-Rs-Cren (Fig. 4C). The freeliving En-Cren was also assayed for PAA production in LB broth as well as CM. PAA secreted by the bacteria, if any, into LB broth was below our limit of detection $(1.0 \mathrm{ng} / \mu \mathrm{l})$, and $2.5 \mathrm{ng} / \mu \mathrm{l}$ in $\mathrm{CM}$. Whereas no difference was observed for radial growth (data not shown), the dry weight, however, of 21-day-old mycelia of curedRs-Cren, determined as previously described (Siddiqui and Shaukat 2005), was significantly greater than for Rs-Cren and restored-RsCren, respectively (Fig. 4C).

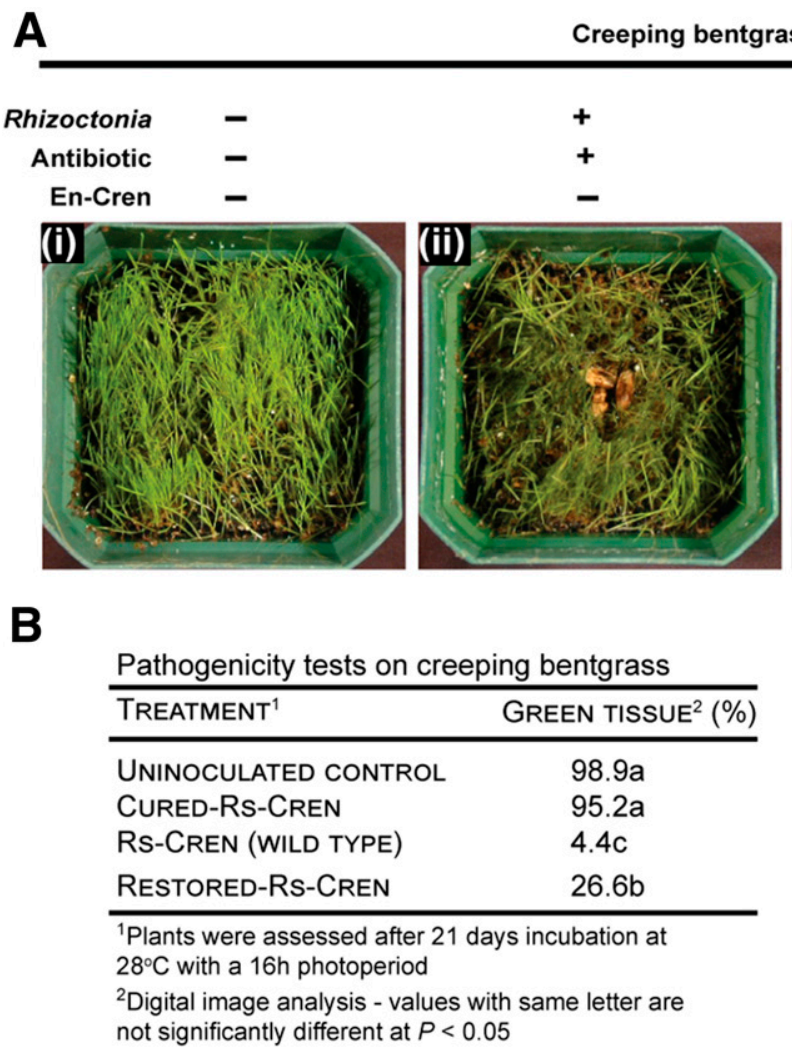

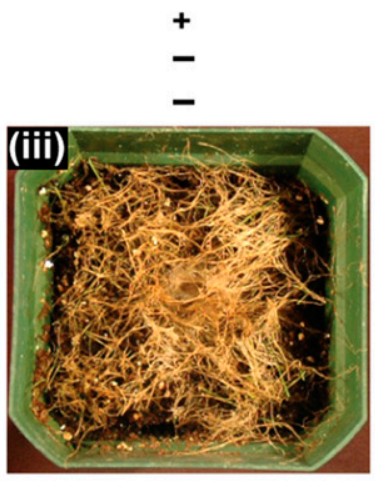
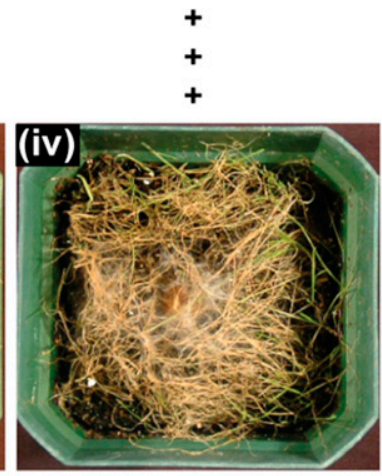

C

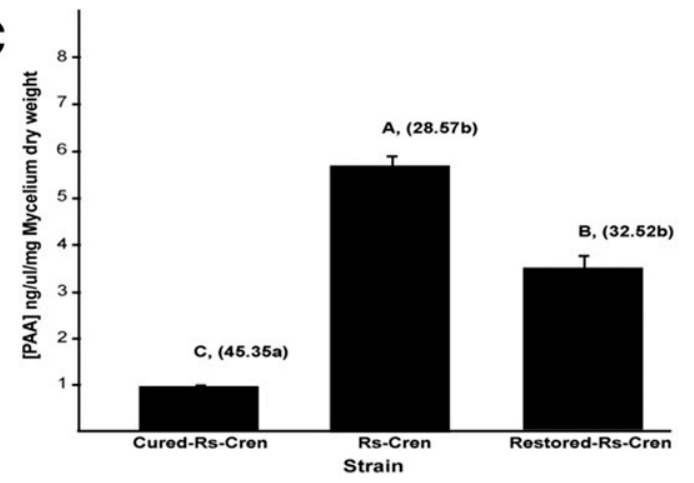

Fig. 4. Assessment for phenotypic differences of fungal strains. A, Disease symptoms of (i) mock-inoculated, (ii) cured-Rs-Cren, (iii) Rs-Cren, and (iv) restored-Rs-Cren pathogenicity on creeping bentgrass cultivar Crenshaw at 21 days postinoculation and incubation under high relative humidity ( $>90 \%$ ), at $30^{\circ} \mathrm{C}$ and $13 \mathrm{~h}$ photoperiod. B, Virulence assay based on percentage of green tissue within $3 \times 3 \mathrm{~cm}^{2}$ area in inoculated pots, estimated by analysis of digital images with SigmaScan Pro version 5.0 software, was significantly higher for the noninoculated (mock) control and cured-Rs-Cren compared with Rs-Cren and restored-Rs-Cren. C, Phenylacetic acid production by cured-Rs-Cren, Rs-Cren, and restored-Rs-Cren, with standard error bars, respectively, following incubation in complete media at room temperature for 21 days in the dark. Values followed by the same letter are not statistically different $(P \leq 0.05)$. Values in parentheses represent average mycelia dry weight (milligrams) from two independent experiments with three replicates each. 
Wild-type Rs-Cren and cured-Rs-Cren are genetically identical. To determine whether changes in the fungal genomes occurred during the antibiotic treatment, both the wild-type and cured strains were subjected to genome sequencing using a GBS approach. In total, 417,938 and 893,599 clean $2 \times 150$-bp pairedend reads were generated for the wild-type and cured strains, respectively. More than $65 \%$ paired-end reads from both datasets can be confidently and uniquely mapped to a draft genome assembly of an R. solani (AG 2-2IIIB) (Fig. 5A). The alignments were used to identify SNPs of each strain versus the draft genome sequence. Of all the 13,923 common SNP sites, the nucleotide types between the two strains were identical (Fig. 5B). Additionally, normalized read depths of $20 \mathrm{~kb}$ windows were compared, no obvious differences were observed (Fig. 5C and D) for all the examined windows. Therefore, no evidence for DNA changes was identified to suggest any genetical difference between the wild-type and cured strains of Rs-Cren.

\section{DISCUSSION}

The persistent presence of bacteria with $R$. solani hyphae during culture led to the discovery of an intimate association of a common soil bacterium, which is related to the genus Enterobacter, and an isolate of $R$. solani AG 2-2IIIB. The persistence of the bacterium in the absence of visible extracellular growth on hyphae led us to hypothesize that the bacteria could exist either in very tight association with the extracellular hyphal wall or as an endosymbiont of the fungus. While the bacterium may have an affinity for fungal hyphae, the evidence indicates that the bacterium exists as an endohyphal resident of $R$. solani. Bacterial DNA was detected by PCR analysis of surface-sterilized wild-type mycelia of Rs-Cren, and no bacteria were recovered from hyphal washes following incubation. These culture and sequence-based approaches were, however, not sufficient to eliminate all possibility that the bacteria tightly associated with the external hyphal wall and was protected from surface sterilization. The observation of bacterial shaped bodies within sheared as well as intact hyphae indicated an internal association. No extracellular bacteria-like structures were observed from backscatter electron imaging of intact wild-type hyphae that lacked visible bacterial contamination in culture. Furthermore, we demonstrated that GFP-labeled En-Cren could exist intracellularly in Rs-Cren hyphae upon co-cultivation of the two organisms. The GFP-labeled bacteria persisted upon fungal culture and during infection of rice stem tissue with the fungus.

The results also indicated that the bacterium contributes to brown patch disease. The virulence of $R$. solani Rs-Cren was reduced on creeping bentgrass by the removal of Enterobacter $\mathrm{sp}$. En-Cren upon culture with antibiotics, and virulence was restored upon reintroduction of En-Cren. A number of studies have proposed that PAA (or hydroxylated variants) functions as a virulence factor for some strains of $R$. solani (Bartz et al. 2012). Here, the cured strain of Rs-Cren had reduced PAA content in culture filtrates. The removal of the bacteria from Rs-Cren also had no effect on radial hyphal growth rates of cured-Rs-Cren on plates. However, the dry mycelia weight of cured-Rs-Cren was greater than for Rs-Cren and restoredRs-Cren in liquid medium. This finding indicates that the lower PAA production by cured-Rs-Cren was likely not due to reduced fungal growth. The significantly greater dry mycelia weight of the cured-Rs-Cren may indicate a fitness cost to the fungus when carrying the bacterium and grown on laboratory media. The exact nature of the fitness cost imposed by the bacteria is yet to be determined. However, this apparent cost in growth may be compensated for in nature by gains in toxin production, nutrient acquisition, or growth in the soil and/or on the plant host. The involvement of bacteria in PAA biosynthesis is further supported by the elevated PAA production observed with restored-Rs-Cren. However, these results and previous results have not established a causal relationship between PAA and symptom development, as a measure of fungal virulence (Betancourt and Ciampi 2000). The requirement for the bacteria for elevated PAA production and virulence phenotype by the fungus nevertheless questions the accuracy of the current designation of the fungus as the sole causative

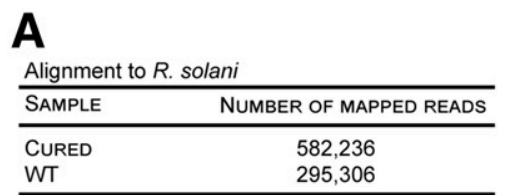

B

\begin{tabular}{lc} 
SNP Analysis & \\
\hline CATEGORY & NUMBER OF SNPS \\
\hline WT = CURED & 13,923 \\
WT $\neq$ CURED & 0 \\
\hline
\end{tabular}

C

D
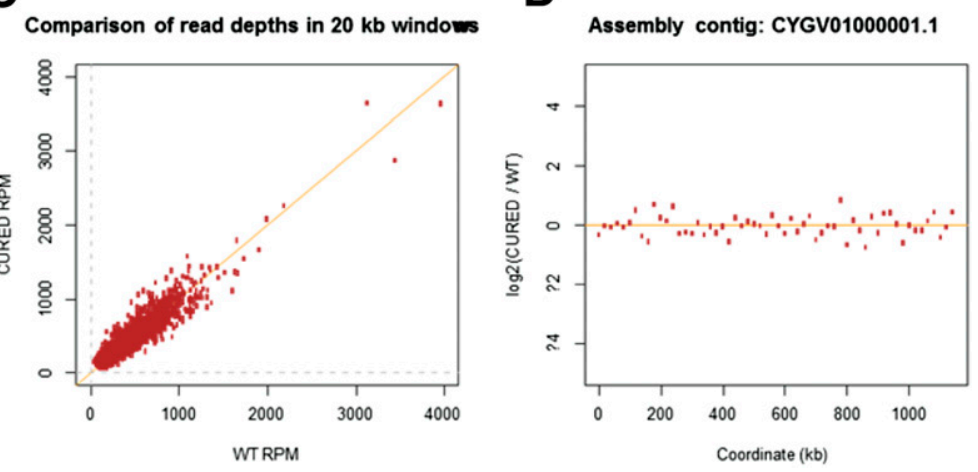

Fig. 5. Genotyping-by-sequencing (GBS) analysis of wild-type and cured Rhizoctonia solani-Cren. A, GBS sample fragments of the genome using the restriction enzyme Bsp1286l. The number of high quality reads that map to the draft genome assembly for $R$. solani AG 2-2IIIB (GenBank accession GCA_00128675) are given. B, The number of single nucleotide polymorphisms identified between cured and wild-type sequence reads where there was a minimum of eight reads for each genomic DNA. C, Distribution of read depth for cured ( $y$-axis) and wild-type along a sliding $20 \mathrm{~kb}$ window of the published genome, indicating that there are no detectible large deletions in either strain in comparison with the other. $\mathbf{D}$, Example of distribution of read depth ratios of cured and wild-type sequence reads along a single contig-here, the largest single sequence contig of AG 2-2IIIB. 
agent of brown patch disease. Further genetic analysis of the bacterium may allow further dissection of the bacterial contribution to PAA biosynthesis and the contribution of PAA to fungal virulence.

GBS analysis was performed to determine if any gross changes had occurred in the multinucleate fungus during culture and the antibiotic treatment process. The GBS analysis did not reveal any gross changes between the wild-type and cured strains. The ability to restore virulence with the restoration of the bacteria also is not consistent with genetic instability of the fungus itself.

The results also raise the possibility that fungi serve as vectors for entry of bacteria into plant tissues. The bacterial endosymbiont of Rs-Cren is most closely related to members of the genus Enterobacter, which encompasses a broad range of strains isolated from diverse environment. Enterobacter species have been identified as soil microflora, endophytes, biocontrol agents, opportunistic animal pathogens, and some have been reported as plant pathogens (Grimont and Grimont 2006). A puzzling observation was that the bacteria in wild-type intact hyphae or bacteria in restored hyphae did not assume a clear rod shape, which is typical of Enterobacter. The spherical nature of the GFP-expressing cells supported the conclusion that the bacteria assume a spherical morphology within the fungus, and the binding of an Enterobacter anti-OmpA antibody to spherical bodies in the hyphae also provided further evidence of this hypothesis. Additionally, the observation of spherical-shaped extra-hyphal GFP-expressing bacteria in rice sheath cells following inoculation with restored-Rs-Cren ${ }^{\text {EnGFP }}$ provided additional evidence of dimorphism in the Enterobacter sp. En-Cren. Bacteria are known to occur as L-forms under specific environments, including host tissues, although L-forms have not been reported for endosymbiotic bacteria of fungi (Partida-Martinez et al. 2007). R. solani may harbor cytoplasmic or lysosomal lysozymes that inhibit cell wall formation or damage the bacterial cell wall while permitting replication and survival.

The endosymbiotic association of bacteria with $R$. solani AG 22IIIB further complicates the genetics of Rhizoctonia, which was first described over 150 years ago and of which we have little understanding (Kühn 1858). Several fungal metabolites, including several toxins, have been associated with the pathogenicity of several $R$. solani AGs (Bertagnolli et al. 1996; González-García et al. 2006; Liu and Sinclair 1993). Low virulence in certain strains of $R$. solani have also been described, and although the exact underlying basis are unknown, defects have been attributed to chromosomal heterozygosity and virus attenuation (Liu et al. 2003; Tavantzis and Lakshman 1995; Zheng et al. 2014). This result raises the possibility that other $R$. solani-associated diseases involve bacterial contributions and reveal the potential of fungi as important vectors for bacteria into plant tissues. We anticipate the discovery of bacterial endosymbionts in additional $R$. solani AGs as well as other Rhizoctonia species. Our preliminary findings from the analysis of two other $R$. solani AG 2-2IIIB strains from tall fescue (Festuca arundinacea Schreb.) and perennial ryegrass (Lolium perenne L.), both cool-season turfgrasses, similarly revealed the presence of endohyphal bacteria. Interestingly, Rhizoctonia root and crown rot of sugar beet was recently shown to be aggravated by a subspecies of the bacterium Leuconostoc mesenteroides (Strausbaugh 2016). The extent of the association between the fungus and the Leuconostoc sp. was however not reported.

The ability to reintroduce the bacterium into cured fungal isolates by co-cultivation is fortunate and will facilitate genetic analyses of the bacterium - fungus - plant interaction. In a broader context, new bacterial endosymbionts of endosymbiotic fungi have also been identified in which the bacterium may contribute beneficial properties to the fungal-plant interaction, and recently, the ability to reintroduce bacteria into a plant fungal endosymbiont was also demonstrated (Arendt et al. 2016; Hoffman et al. 2013). These results, hopefully, will lead to a more thorough understanding of the genetics of multicomponent phytobiome interactions. This could in turn facilitate the development of new, effective, and environmentfriendly strategies for disease management. The genetic requirements of Enterobacter sp. En-Cren on $R$. solani Rs-Cren virulence are under investigation.

\section{ACKNOWLEDGMENTS}

We thank P. Wangemann and J. Sanneman of the COBRE Core B Facility (NIH-P20-RR017686) at Kansas State University for the use of Zeiss LSM 700 confocal microscope, and A. Ahkunova of the Integrated DNA Facility at Kanas State University. This work was supported by funds provided by the University of Florida and IOS-1258028 from the National Science Foundation (FW). We thank R. Todd for comments in the preparation of the manuscript.

\section{LITERATURE CITED}

Anderson, N. A. 1982. The genetics and pathology of Rhizoctonia solani. Annu. Rev. Phytopathol. 20:329-347.

Arendt, K. R., Hockett, K. L., Araldi-Brondolo, S. J., Baltrus, D. A., and Arnold, A. E. 2016. Isolation of endohyphal bacteria from foliar Ascomycota and in vitro establishment of their symbiotic associations. Appl. Environ. Microbiol. 82:2943-2949.

Arias, R. S., Power, I. L., Culbreath, A. K., Sobolev, V. S., and Lamb, M. C. 2013. First report of Pantoea ananatis (syn. Erwinia uredovora) being associated with peanut rust in Georgia. Published Online. Plant Health Progress doi:10.1094/ PHP-2013-0729-04-BR

Bandy, B. P., and Tavantzis, S. M. 1990. Effect of hypovirulent Rhizoctonia solani on Rhizoctonia disease, growth and development of potato plants. Am. Potato J. 67:189-199.

Bartz, F. E., Glassbrook, N. J., Danehower, D. A., and Cubeta, M. A. 2012. Elucidating the role of the phenylacetic acid metabolic complex in the pathogenic activity of Rhizoctonia solani anastomosis group 3. Mycologia 104:793-803.

Bertagnolli, B. L., Dal Soglio, F. K., and Sinclair, J. B. 1996. Extracellular enzyme profiles of the fungal pathogen Rhizoctonia solani isolate $2 \mathrm{~B}-12$ and two antagonists, Bacillus megaterium strain B153-2-2 and Trichoderma harzianum isolate Th008. I. Possible correlations with inhibition of growth and biocontrol. Physiol. Mol. Plant Pathol. 48:145-160.

Bertaux, J., Schmid, M., Prevost-Boure, N. C., Churin, J. L., Hartmann, A., Garbaye, J., and Frey-Klett, P. 2003. In situ identification of intracellular bacteria related to Paenibacillus spp. in the mycelium of the ectomycorrhizal fungus Laccaria bicolor S238N. Appl. Environ. Microbiol. 69:4243-48.

Betancourt, O., and Ciampi, L. 2000. Contribution to the study and control of Rhizoctonia solani. I. extraction and bioassay of phenylacetic acid phytotoxicity produced in vitro by $R$. solani AG-3. Fitopatologia 35:119-125.

Bianciotto, V., Genre, A., Jargeat, P., Lumini, E., Bécard, G., and Bonfante, P. 2004. Vertical transmission of endobacteria in the arbuscular mycorrhizal fungus Gigaspora margarita through generation of vegetative spores. Appl. Environ. Microbiol. 70:3600-8.

Bolger, A. M., Lohse, M., and Usadel, B. 2014. Trimmomatic: A flexible trimmer for Illumina sequence data. Bioinformatics 30:2114-2120.

Brookhouser, L. W., and Weinhold, A. R. 1979. Induction of polygalacturonase from Rhizoctonia solani by cotton see and hypocotyl exudates. Phytopathology 69:599-602.

Brooks, S. A. 2007. Sensitivity to a phytotoxin from Rhizoctonia solani correlates with sheath blight susceptibility in rice. Phytopathology 97: 1207-1212.

Bryksin, A. V., and Matsumura, I. 2010. Rational design of a plasmid origin that replicates efficiently in both gram-positive and gram-negative bacteria. PLoS ONE 5:e13244.

Carling, D. E. 1996. Grouping in Rhizoctonia solani by hyphal anastomosis. Pages 37-47 in: Rhizoctonia Species: Taxonomy, Molecular Biology, Ecology, Pathology, and Disease Control. B. Sneh, S. Jabaji-Hare, S. Neate, and G. Dijst, eds. Kluwer Academic Publishers, Dordrecht, The Netherlands. 
Carling, D. E., Kuninaga, S., and Brainard, K. A. 2002. Hyphal anastomosis reactions, rDNA-internal transcribed spacer sequences, and virulence levels among subsets of Rhizoctonia solani anastomosis group-2 (AG-2) and AGBI. Phytopathology 92:43-50.

Correll, J. C., Klittich, C. J. R., and Leslie, J. F. 1987. Nitrate nonutilizing mutants of Fusarium oxysporum and their use in vegetative compatibility tests. Phytopathology 77:1640-1646.

Desper, R., and Gascuel, O. 2004. Theoretical foundation of the balanced minimum evolution method of phylogenetic inference and its relationship to weighted least-squares tree fitting. Mol. Biol. Evol. 21:587-598.

Elshire, R. J., Glaubitz, J. C., Sun, Q., Poland, J. A., Kawamoto, K., Buckler, E. S., and Mitchell, S. E. 2011. A robust, simple genotyping-by-sequencing (GBS) approach for high diversity species. PLoS ONE 6:e19379.

González-García, V., Portal Onco, M. A., and Rubio Susan, V. 2006. Review, biology and systematics of the form genus Rhizoctonia. Span. J. Agric. Res. 4:55-79.

Grimont, F., and Grimont, P. A. D. 2006. The Genus Enterobacter. Pages 197-214 in: The Prokaryotes, Vol. 6, Proteobacteria: Gamma Subclass. M. Dworkin, S. Falkow, E. Rosenberg, K. H. Schleifer, and E. Stackebrandt, eds. Springer, Berlin.

Herr, L. J. 1996. Sugar beet diseases incited by Rhizoctonia spp. Pages 341-349 in: Rhizoctonia Species: Taxonomy, Molecular Biology, Ecology, Pathology and Disease Control. B. Sneh, S. Jabaji-Hare, S. Neate, and G. Dijst, eds. Kluwer Academic Publishers, Dordrecht, The Netherlands.

Hoffman, M. T., Gunatilaka, M. K., Wijeratne, K., Gunatilaka, L., and Arnold, A. E. 2013. Endohyphal bacterium enhances production of indole-3-acetic acid by a foliar fungal endophyte. PLoS ONE 8:e73132.

Hoffman, T. M., and Arnold, A. E. 2010. Diverse bacteria inhabit living hyphae of phylogenetically diverse fungal endophytes. Appl. Environ. Microbiol. 76: 4063-4075.

Hoffman, T. W., and Jongebloed, P. H. J. 1988. Infection process of Rhizoctonia solani on Solanum tuberosum and effects of granular nematicide. Neth. J. Plant Pathol. 94:243-252.

Kankanala, P., Czymmek, K., and Valent, B. 2007. Roles for rice membrane dynamics and plasmodesmata during biotrophic invasion by the blast fungus. Plant Cell 19:706-724.

Karcher, D. E., and Richardson, M. D. 2005. Batch analysis of digital images to evaluate turfgrass characteristics. Crop Sci. 45:1536-1539.

Kobayashi, D. Y., and Crouch, J. A. 2009. Bacterial/fungal interactions: From pathogen to mutualistic endosymbionts. Annu. Rev. Phytopathol. 47:63-82.

Kühn, J. G. 1858. Die Krankheiten der Kulturegewachse, ihre Ursachen and ihre Verhutung. Gustav Bosseimann, Berlin.

Li, H., and Durbin, R. 2009. Fast and accurate short read alignment with Burrows-Wheeler transform. Bioinformatics 25:1754-1760.

Li, R., Zhu, H., Ruan, J., Qian, W., Fang, X., Shi, Z., Li, Y., Li, S., Shan, G., Kristiansen, K., Li, S., Yang, H., Wang, J., and Wang, J. 2010. De novo assembly of human genomes with massively parallel short read sequencing. Genome Res. 20:265-272.

Liu, C., Lakshman, D. K., and Tavantzis, S. M. 2003. Quinic acid induces hypovirulence and expression of a hypovirulence-associated double-stranded RNA in Rhizoctonia solani. Curr. Genet. 43:103-111.
Liu, Z. L., and Sinclair, J. B. 1993. Differentiation of intraspecific groups within anastomosis group 1 of Rhizoctonia solani using ribosomal DNA internal transcribed spacer and isozyme comparisons. Can. J. Plant Pathol. 15: 272-280.

McKenna, A., Hanna, M., Banks, E., Sivachenko, A., Cibulskis, K., Kernytsky, A., Garimella, K., Altshuler, D., Gabriel, S., Daly, M., and DePristo, M. A. 2010. the genome analysis toolkit: A MapReduce framework for analyzing next-generation DNA sequencing data. Genome Res. 20:1297-1303.

Myra, N. W., Fluit, A. D. C., and Jan, V. 1994. Rapid identification of bacteria by PCR-single-strand conformation polymorphism. J. Clin. Microbiol. 32: 3002-3007.

Obasa, K., Fry, J., Bremer, D., St. John, R., and Kennelly, M. 2013. Effect of cultivation and timing of nitrogen fertilization on large patch disease of zoysiagrass. Plant Dis. 97:1075-1081.

Ogoshi, A. 1987. Ecology and pathogenicity of anastomosis and intraspecific groups of Rhizoctonia solani Kuhn. Annu. Rev. Phytopathol. 25:125-143.

Partida-Martinez, L. P., Groth, I., Schmitt, I., Richter, W., Roth, M., and Hertweck, C. 2007. Burkholderia rhizoxinica sp. nov. and Burkholderia endofungorum sp. nov., bacterial endosymbionts of the plant-pathogenic fungus Rhizopus microsporus. Int. J. Syst. Evol. Microbiol. 57:25832590 .

Partida-Martinez, L. P., and Hertweck, C. 2005. Pathogenic fungus harbors endosymbiotic bacteria for toxin production. Nature 437:884-888.

Siddiqui, I. A., and Shaukat, S. S. 2005. Phenylacetic acid-producing Rhizoctonia solani represses the biosynthesis of the nematicidal compounds in vitro and influences biocontrol of Meloidogyne incognita in tomato by Pseudomonas fluorescens strain CHA0 and it GM derivatives. J. Appl. Microbiol. 98:43-55.

Sneh, B., Ichielevich-Auster, M., and Plaut, Z. 1989. Mechanism of seedling protection induced by a hypovirulent isolate of Rhizoctonia solani. Can. J. Bot. 67:2135-2141.

Strausbaugh, C. A. 2016. Leuconostoc spp. associated with root rot in sugar beet and their interaction with Rhizoctonia solani. Phytopathology 106:432-441.

Tavantzis, S. M., and Lakshman, D. K. 1995. Virus-like double-stranded RNA elements and hypovirulence in phytopathogenic fungi. Pages 249-267 in: Pathogenesis and Host-Parasite Specificity in Plant Disease: Histopathological, Biochemical, Genetic and Molecular Basis. Vol. III. K. Kohmoto, R. P. Singh, and U. S. Singh, eds. Elsevier (Pergamon) Press, Oxford.

Vidhyasekaran, P., Ruby Ponmalar, T., Samiyappan, R., Velazhahan, R., Vimala, R., Ramanathan, A., Paranidharan, V., and Muthukrishnan, S. 1997. Host-specific toxin production by Rhizoctonia solani, the rice sheath blight pathogen. Phytopathology 87:1258-1263.

Yokoyama, K., Ogoshi, A., and Ui, T. 1985. Studies on hyphal anastomosis of Rhizoctonia solani. II. The ultrastructural changes of hyphal cells during perfect fusion. Trans. Mycol. Soc. Jpn. 26:199-207.

Zheng, L., Zhang, M., Chen, Q., Zhu, M., and Zhou, E. 2014. A novel mycovirus closely related to viruses in the genus Alphapartitivirus confers hypovirulence in the phytopathogenic fungus Rhizoctonia solani. Virology 456-457: 220-226. 